\title{
Effect of HIV infection on time to recovery from an acute manic episode
}

This article was published in the following Dove Press journal:

HIVIAIDS - Research and Palliative Care

28 September 2010

Number of times this article has been viewed

\section{E Nakimuli-Mpungu' ${ }^{1,2,3}$ \\ B Mutamba ${ }^{2,3}$ \\ S Nshemerirwe ${ }^{2,3}$ \\ MS Kiwuwa ${ }^{4}$ \\ S Musisi}

'Mental Health Department, Johns Hopkins Bloomberg School of Public Health, Baltimore, Maryland, USA;

${ }^{2}$ Department of Psychiatry, Makerere College of Health Sciences, School of Medicine, Kampala; ${ }^{3}$ Butabika National Referral Mental Hospital, Ministry of Health, Kampala; ${ }^{4} \mathrm{Clinical}$ Epidemiology Unit, Makerere College of Health Sciences, School of Medicine, Kampala, Uganda
Correspondence: Etheldreda Nakimuli-Mpungu Johns Hopkins Bloomberg School of Public Health, Mental Health Department, 624 N Broadway, Hampton House, Rm 784, Baltimore, MD 21205, USA Tel +l 4438394012

Email enakimul@jhsph.edu
Introduction: Understanding factors affecting the time to recovery from acute mania is critical in the management of manic syndromes. The aim of this study was to determine the effect of HIV infection on time to recovery from acute mania.

Methods: We performed a retrospective study in which medical charts of individuals who were treated for acute mania were reviewed. Survival analysis with Cox regression models were used to compare time to recovery from an acute manic episode between human immunodeficiency virus (HIV)-positive individuals and HIV-negative individuals.

Results: Median survival time was one week for HIV-positive individuals and more than four weeks for HIV-negative individuals $\left(\chi^{2}=18.4, P\right.$ value $\left.=0.000\right)$. HIV infection was the only marginally significant independent predictor of survival probability on the acute admission ward (hazards ratio 2.87, $P=0.06$ ).

Conclusion: Acute mania in HIV-infected persons responds faster to psychotropic drugs compared with that in HIV-negative persons.

Keywords: HIV-related mania, bipolar disorder, HIV infection, Uganda, immunodeficiency virus

\section{Introduction}

In the past five years, an increasing body of evidence has accumulated describing the mental health problems of persons living with immunodeficiency virus (HIV)/acquired immunodeficiency syndrome (AIDS) in Uganda. ${ }^{1-5}$ These problems may be pre-existing mental illnesses in an individual who becomes secondarily infected with HIV or they may develop because of the direct or indirect effects of the HIV virus on the brain. ${ }^{6}$ For example, we have previously described the clinical presentation of individuals with acute mania and HIV infection. ${ }^{7}$ Our research has shown that such individuals could have HIV-related secondary mania or bipolar disorder mania. HIV-positive individuals with bipolar disorder mania had more cognitive impairment, more immune suppression, more severe respiratory tract infections, and more current use of antituberculosis therapy compared with individuals with HIV-related secondary mania. ${ }^{7}$

Hospital data consistently show that bipolar disorder is the most common mental disorder seen at Butabika Hospital, Uganda's only psychiatric hospital, accounting for $30 \%-35 \%$ of all first psychiatric hospitalizations annually. The prevalence of HIV infection among individuals with a first psychiatric hospitalization for severe mental disorder is estimated at $18 \%$, which is three times the rate in the general population. ${ }^{8}$ The literature on treatment outcomes of HIV-positive individuals with severe mental illness, such as bipolar disorder, is limited in low-resource settings like Uganda. 
In the context of HIV/AIDS, descriptive and treatment studies of acute mania in HIV-infected persons is lacking in developing countries. In developed countries, comprehensive reviews of the literature have provided compelling evidence that both typical and atypical antipsychotics are effective in the treatment of manic episodes in mentally ill, HIV-infected

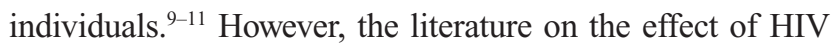
infection in response to these treatments is limited. No study has compared the recovery time of HIV-positive individuals with acute mania with that of HIV-negative individuals with acute mania. Studies that we have performed comparing the clinical presentation of bipolar disorder mania versus that of HIV-related mania provided us with an opportunity to investigate the effect of HIV infection on time to recovery from an acute manic episode retrospectively. From our previous crosssectional studies, we had noted a quicker response to psychotropic drugs among HIV-positive individuals compared with HIV-negative individuals with an acute manic episode. ${ }^{12}$

The aim of this study was to explore this finding further, using a survival analysis technique, and investigate its clinical implications in the care of HIV-positive individuals in Uganda and other low-resource settings. We hypothesized that individuals with HIV infection would have a shorter time to recovery from an acute manic episode compared with those without HIV infection.

\section{Material and methods}

A random subsample of 60 medical charts were obtained from a sample of 155 medical charts of patients who, in 2004-2006, had participated in a previous study that described the clinical presentation of bipolar disorder mania in Butabika hospital. ${ }^{7}$ To obtain a random sample, we made a list of inpatient identification numbers for patients who had participated in the previous study. Unique numbers $1-155$ were assigned to each inpatient number. Pieces of paper labeled with these unique numbers were placed in a box and on each day of data collection, research assistants randomly picked 10 pieces of paper. The inpatient number corresponding with the number on the piece of paper was then used to trace the medical chart from the medical records office. Research assistants reviewed the medical charts and extracted data on variables of interest in this study. Medical charts that had incomplete data on variables of interest were excluded from the study. This process was repeated until we obtained a subsample of 60 medical charts.

These medical charts belonged to individuals aged 18 years and older, with a first episode of acute mania and without a history of substance or alcohol dependence. In addition, these study participants had not met the Diagnostic and Statistical
Manual for Mental Disorders, Fourth edition (DSM-IV) criteria $^{13}$ for delirium or a substance use disorder, and were not in the puerperium period. They had to have a laboratory record of their HIV serostatus, and a record of the dates of admission and discharge from the acute admission ward. In addition, study participants had to have sufficient data on other explanatory variables of interest including gender, age, years of education, source of referral, and treatment combination (whether patient was treated with an antipsychotic alone or in combination with a mood stabilizer or other drug).

The outcome of interest was time from psychotropic drug initiation (on the date of admission) to discharge from the acute admission ward. The decision to discharge a patient is made during major ward rounds that are conducted twice a week. The psychiatrist in charge of an acute admission ward, together with other members of the psychiatric team, carry out assessments based on DSM-IV criteria and make a decision as to whether a patient is fit for discharge or not. For acute mania, the decision to discharge an individual who was admitted with acute mania is based on the absence of all DSM-IV criteria for manic symptoms that were present at the time of admission. In this study, the "failure event" was considered as being discharge within four weeks of the date of admission. The Butabika Hospital Research Committee approved the study.

\section{Statistical analysis}

Statistical analysis was performed using Stata 10.0 (Stata Corp., College Station, TX).

Bivariate analyses were conducted to identify demographic and clinical variables that were significantly correlated with HIV-positive status at the time of admission. We used Chisquare tests or Fisher's Exact test for qualitative variables, and independent sample t-tests for continuous variables.

We computed Kaplan-Meier estimates and log-rank Chisquare tests to determine the impact of study variables on survival in the acute admission wards. Study variables that were statistically significantly associated with HIV status and survival at $P<0.05$ were entered into a Cox regression model to control for their effect when assessing the effect of HIV infection on time to recovery from an acute manic episode. We used graphical methods and Schoenfeld residuals to assess the proportional hazards assumption.

\section{Results}

There were 60 records selected for the study, but eight records did not have laboratory confirmation of HIV status, so were excluded from the data analysis. The majority of the study participants were HIV-positive (65.4\%) and female (70\%). 
The mean age was 33.6 (standard deviation [SD] 6.9, range 23-55) years. Sixty percent of the participants had more than eight years of formal education, indicating that they had at least attained secondary education level and above. Physicians and general practitioners had referred $34 \%$ of the study sample.

Among HIV-positive individuals, the mean CD4 count was 206 (SD 75.5, range 48-332). None of the HIV-positive individuals had initiated antiretroviral therapy prior to admission. Overall, 39 individuals with acute mania were discharged within four weeks of admission. The study participants had a median time to recovery of 2.35 weeks (mean 2.5, SD 1.59, range 3.5 days-5.0 weeks). Sixty percent of the study participants received monotherapy with one antipsychotic drug, either haloperidol or chlorpromazine. The relationship between the study variables and HIV infection among patients with acute mania is shown in Table 1.

Figures 1 and 2 show the Kaplan-Meier estimates of the survival distribution of time to discharge by HIV status and by mania status, respectively. Median survival time was one week for HIV-positive individuals and more than four weeks among HIV-negative individuals. These differences were statistically significant by the log-rank tests $\left(\chi^{2}=18.4, P=0.000\right.$ and $\chi^{2}=33.6, P=0.000$, respectively). Individuals with HIV-related mania had the shortest median survival time of six days. Males had a median survival time of 3.7 weeks, whereas females had a survival time that averaged two weeks (log-rank test $\chi^{2}=4.97$, $P=0.03)$. Individuals over 30 years of age had a median survival time of 1.1 weeks whereas younger individuals had a survival time that averaged 2.7 weeks (log-rank test $\chi^{2}=7.25$, $P=0.007)$. Individuals referred from general hospitals and clinics had a median survival of one week while those brought by relatives had a median survival time of 3.1 weeks (log-rank test $\left.\chi^{2}=7.11, P=0.03\right)$. Individuals who had monotherapy with one antipsychotic drug had a median survival of one week, whereas those who had combination therapy with two antipsychotics or an antipsychotic and a mood stabilizer had a median survival time of 3.3 weeks (log-rank test $\left.\chi^{2}=11.5, P=0.001\right)$.

Table 2 shows the Cox proportional hazard models for covariates with rate of discharge from acute admission wards. After controlling for study variables that were associated with both HIV and survival probability on the admission wards, HIV infection remained the only marginally significant independent predictor of survival probability on the acute admission wards $(P=0.06)$.

\section{Discussion}

HIV infection emerged as the only marginally significant independent predictor of survival time on the acute admission ward for individuals admitted with acute mania. Individuals with HIV-related mania had the shortest stay on the acute admission ward compared with those with bipolar mania regardless of HIV status. These findings strengthen previous theories that mania secondary to the pathophysiologic effects of the HIV virus on the brain may be different from bipolar mania in HIV-negative individuals. ${ }^{14,15}$ HIV-related mania appears to be more responsive to psychotropic drugs

Table I The relationship between study variables and HIV infection among patients with acute mania

\begin{tabular}{|c|c|c|c|c|}
\hline Characteristic & HIV+ with mania $\mathbf{N}=34 \%$ & HIV- with mania $N=18 \%$ & Odds ratio & $P$-value \\
\hline \multicolumn{5}{|l|}{ Age } \\
\hline Less than 30 yrs & 20.6 & 79.4 & 1 & \\
\hline 30 yrs \& above & 79.4 & 20.6 & 13.5 & $<0.001$ \\
\hline \multicolumn{5}{|l|}{ Gender } \\
\hline Male & 24 & 44 & 1 & \\
\hline Female & 76 & 55 & 2.6 & 0.125 \\
\hline \multicolumn{5}{|l|}{ Education years } \\
\hline Less than $8 \mathrm{yrs}$ & 56 & 11 & 1 & \\
\hline 8 yrs or more & 44 & 89 & 0.1 & 0.005 \\
\hline \multicolumn{5}{|l|}{ Employment } \\
\hline Not employed & 59 & 17 & I & \\
\hline Employed & 41 & 83 & 0.14 & 0.006 \\
\hline \multicolumn{5}{|l|}{ Referral source } \\
\hline Hospital/clinic & 47 & 55.6 & 1 & \\
\hline Relatives & 26.5 & 16.7 & 0.12 & 0.016 \\
\hline Police & 26.5 & 27.7 & 0.24 & 0.128 \\
\hline \multicolumn{5}{|l|}{ Treatment } \\
\hline Antipsychotic & 79.4 & 16.7 & 1 & $<0.001$ \\
\hline Antipsychotic \& & 20.6 & 83.3 & 0.1 & \\
\hline Mood stabilizer & & & & \\
\hline
\end{tabular}

Abbreviation: HIV, human immunodeficiency virus. 


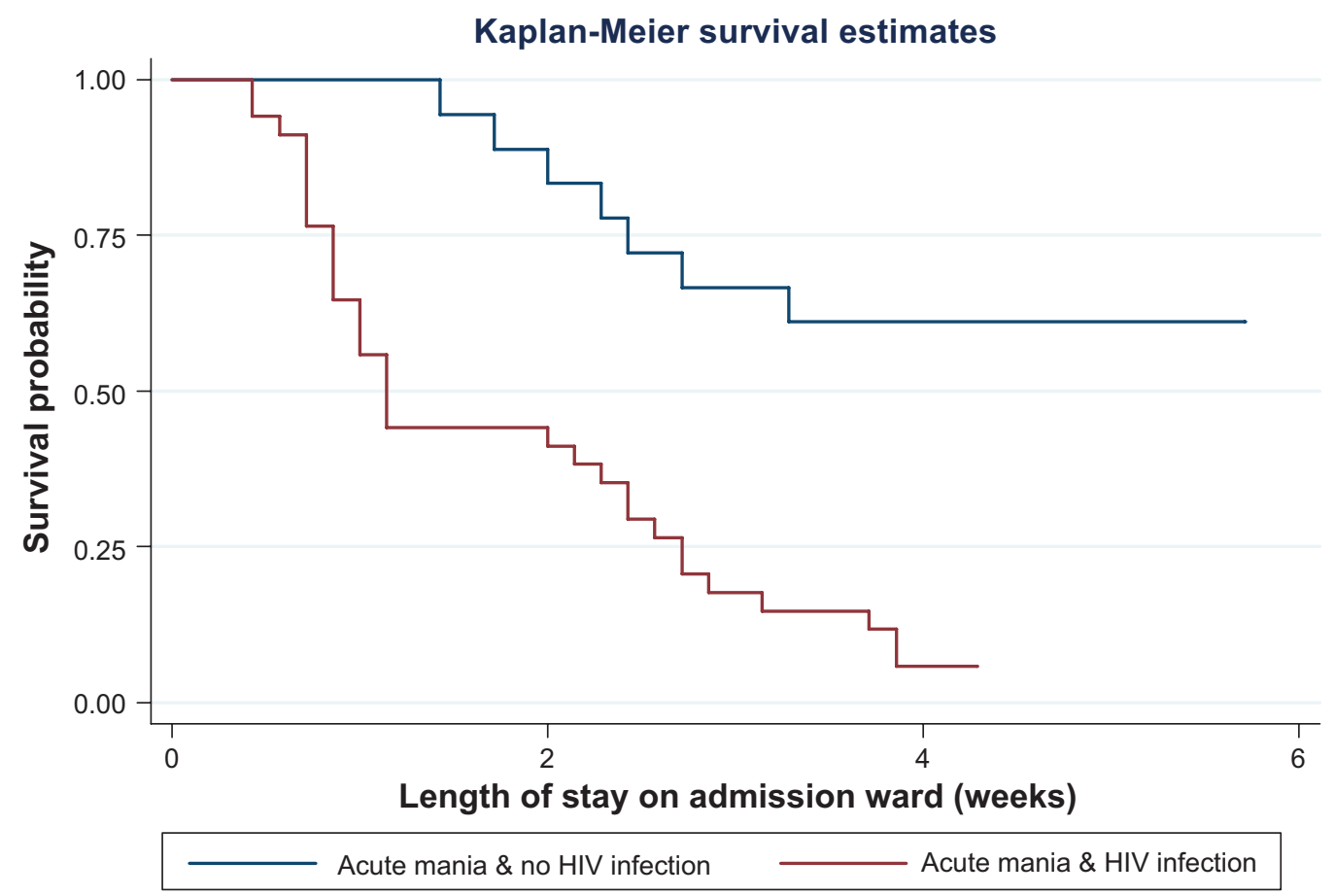

Figure I Kaplan-Meier estimates of the distribution of time until discharge from the admission wards (by HIV status) among individuals admitted with an acute episode of mania. Abbreviation: HIV, human immunodeficiency virus.

than mania in HIV-negative individuals. Previous studies have shown that HIV-related mania is responsive to both typical and atypical antipsychotics, ${ }^{16-18}$ benzodiazepines such as clonazepam, ${ }^{19}$ and electroconvulsive therapy. ${ }^{20}$ However, none of these studies compared responses to these psychotropic drugs between HIV-positive and HIV-negative individuals.

There are several limitations to our study. First, the study sample is small and thus may not have sufficient power to detect significant findings. Second, generalization

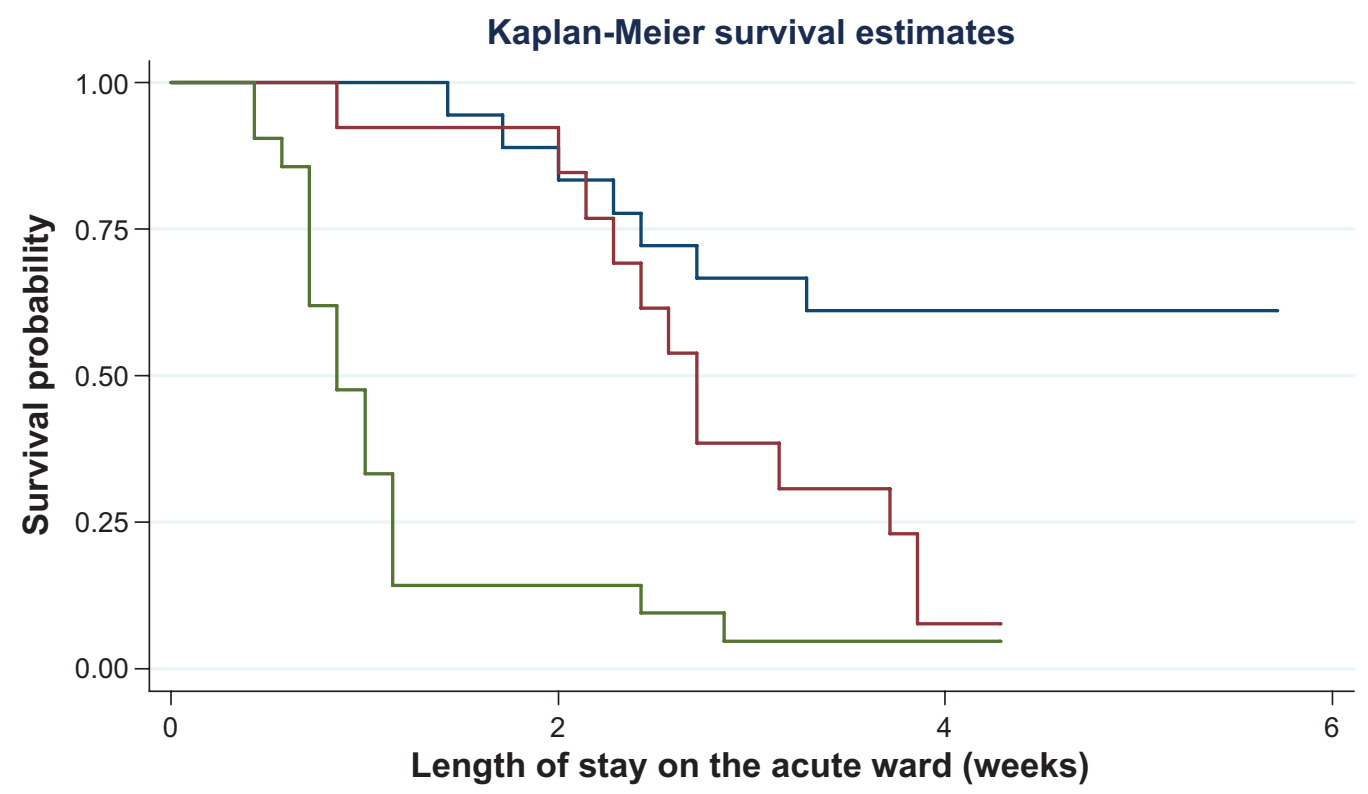

Bipolar mania \& No HIV infection

Bipolar mania with HIV infection

HIV-related Mania

Figure 2 Kaplan-Meier estimates of the distribution of time until discharge from the admission wards (by mania status) among individuals admitted with an acute episode of mania. Abbreviation: HIV, human immunodeficiency virus. 
Table 2 Cox proportional hazard regression models

\begin{tabular}{llll}
\hline Characteristics & Hazard ratio & $\mathbf{9 5 \%} \mathbf{C l}$ & P-value \\
\hline HIV infection & 2.87 & $0.93-8.86$ & 0.06 \\
Female & 1.60 & $0.064-3.94$ & 0.31 \\
30 years and above & 1.72 & $0.76-3.87$ & 0.19 \\
8 or more education years & 0.73 & $0.25-2.08$ & 0.56 \\
Employed & 0.86 & $0.39-1.92$ & 0.72 \\
Referral by relatives & 0.88 & $0.34-2.33$ & 0.81 \\
Referral by police & 2.23 & $0.81-6.16$ & 0.12 \\
Monotheraphy with & 1.55 & $0.50-4.79$ & 0.44 \\
antipsychotics & & &
\end{tabular}

Abbreviations: $\mathrm{HIV}$, human immunodeficiency virus; $\mathrm{Cl}$, confidence interval.

of the findings to other HIV-positive populations is limited because this was a hospital-based study. Third, we could not control for nonadherence, critically ill status, or poor access to care. Finally, we did not have information on prior treatments given before referral to the psychiatric hospital that may have affected outcomes in this study.

Within the context of these limitations, this study points out important clinical implications for the care of HIV-positive individuals in Uganda. The rapid response to psychotropic drugs indicates that if prompt diagnosis of HIV-related manic symptoms is made, then treatment can be given in general medical settings. This will prevent affected individuals from progressing to severe manic states that may disrupt compliance with their treatment regimens. However, such evaluations can only be realized if providers of HIV care have adequate mental health communication skills. Comanagement of mental health problems should be an integrative part of HIV treatment and prevention programs.

We conclude that acute mania in HIV-infected persons responds faster to psychotropic drugs compared with responses in HIV-negative persons. Further prospective studies of treatment of mental health problems in HIVinfected persons should be pursued aggressively to inform the holistic management of HIV-positive individuals in Uganda.

\section{Disclosure}

The authors report no conflict of interest in this work.

HIV/AIDS - Research and Palliative Care

\section{Publish your work in this journal}

HIV/AIDS - Research and Palliative Care is an international, peerreviewed open-access journal focusing on advances in research in HIV, its clinical progression and management options including antiviral treatment, palliative care and public healthcare policies to control viral spread. The journal welcomes original research, basic science,

\section{References}

1. Sacktor NC, Wong M, Nakasujja N, et al. The International HIV Dementia Scale: A new, rapid screening test for HIV dementia. AIDS. 2005;19:1367-1374.

2. Wong MH, Robertson K, Nakasujja N, et al. Frequency of and risk factors for HIV dementia in an HIV clinic in sub-Saharan Africa. Neurology. 2007;68(5):350-355.

3. Musisi S, Kinyanda E. Psychiatric problems of HIV/AIDS and their management in Africa. Makerere University, Kampala: Fountain Publishers; 2009.

4. Musisi S, Kinyanda E. Emotional and behavioral disorders in HIV seropositive adolescents in urban Uganda. East Afr Med J. 2009;86(1):16-24.

5. Nakimuli-Mpungu E, Musisi S, Kiwuwa Mpungu S, Katabira E. Early-onset versus late-onset HIV-related secondary mania in Uganda. Psychosomatics. 2008;49(6):530-534.

6. Cruess DG, Evans DL, Repetto MJ, Gettes D, Douglas SD, Petitto JM. Prevalence, diagnosis, and pharmacological treatment of mood disorders in HIV disease. Biol Psychiatry. 2003;54(3):307-316.

7. Nakimuli-Mpungu E, Musisi S, Mpungu SK, Katabira E. Clinical presentation of bipolar mania in HIV-positive patients in Uganda. Psychosomatics. 2009;50(4):325-330.

8. Maling S, Grosskurth H, Musisi S, Onen T. HIV infection among firsttime admission patients with severe mental illness at Butabika and Mulago Hospitals. Proceedings from the Makerere University Faculty of Medicine, First Annual Scientific Conference, Nov 24-26, 2005, Entebbe, Uganda.

9. Repetto MJ, Petitto JM. Psychopharmacology in HIV-infected patients. Psychosom Med. 2008;70(5):585-592.

10. Vlassova N, Angelino AF, Treisman GJ. Update on mental health issues in patients with HIV infection. Curr Infect Dis Rep. 2009;11(2):163-169.

11. Angelino AF, Treisman GJ. Management of psychiatric disorders in patients infected with human immunodeficiency virus. Clin Infect Dis. 2001;33(6):847-856.

12. Nakimuli-Mpungu E, Musisi S, Mpungu SK, Katabira E. Primary mania versus HIV-related secondary mania in Uganda. Am J Psychiatry. 2006;163(8):1349-1354, quiz 1480.

13. American Psychiatric Association: Diagnostic and Statistical Manual of Mental Disorders, 4th Ed., International Version. Washington, DC: American Psychiatric Association; 1995.

14. Lyketsos CG, Schwartz J, Fishman M, Treisman G. AIDS mania. J Neuropsychiatry Clin Neurosci. 1997;9(2):277-279.

15. Treisman G, Fishman M, Schwartz J, Hutton H, Lyketsos C. Mood disorders in HIV infection. Depress Anxiety. 1998;7(4):178-187.

16. Singh AN, Golledge H, Catalan J. Treatment of HIV-related psychotic disorders with risperidone: A series of 21 cases. J Psychosom Res. 1997;42(5):489-493.

17. Ellen SR, Judd FK, Mijch AM, Cockram A. Secondary mania in patients with HIV infection. Aust N Z J Psychiatry. 1999;33(3):353-360.

18. Mijch AM, Judd FK, Lyketsos CG, Ellen S, Cockram A. Secondary mania in patients with HIV infection: Are antiretrovirals protective? J Neuropsychiatry Clin Neurosci. 1999;11(4):475-480.

19. Budman CL, Vandersall TA. Clonazepam treatment of acute mania in an AIDS patient. J Clin Psychiatry. 1990;51(5):212.

20. Ferrando SJ, Nims C. HIV-associated mania treated with electroconvulsive therapy and highly active antiretroviral therapy. Psychosomatics. 2006;47(2):170-174.

\section{Dovepress}

clinical \& epidemiological studies, reviews \& evaluations, expert opinion \& commentary, case reports \& extended reports. The manuscript management system is completely online and includes a very quick and fair peer-review system. Visit http://www.dovepress.com/ testimonials.php to read real quotes from published authors. 